\title{
PRACTICAL USE OF HIGH-RESOLUTION 20 MHZ ULTRASONOGRAPHY IN DERMATOVENEROLOGY
}

\author{
KOZAROVA A, MINARIKOVA E, PAPPOVA T \\ Comenius University Jessenius Faculty of Medicine and University Hospital, Department of Dermatovenerology, \\ Martin, Slovak Republic
}

\begin{abstract}
High-frequency skin ultrasonography using Dermascan C, manufactured by Cortex Technology, is an important part of modern diagnostic procedure of various skin diseases. It has been used in dermatology since 1979, when it was first used for the measurement of cutaneous thickness. Ultrasonography is a universal, painless, lowrisk and non-invasive procedure that can easily be performed and repeated. It provides real-time visual information about the processes in the skin. This technique has grown to become frequent imaging method in dermatology.

Skin ultrasonography is usually applied in the assessment of skin tumours, inflammatory or fibrosing skin diseases. The main application of ultrasonography in dermatovenerology is a preoperative thickness measurement of malignant melanoma. There is an excellent correlation between ultrasonographic and histological measurements of melanomas thickness. Moreover, information about the lesion quality and the inner structure can be obtained. In this article authors present the possibility of using high-frequency $20 \mathrm{MHz}$ ultrasonography in dermatovenerology.
\end{abstract}

Keywords: High-frequency $20 \mathrm{MHz}$ ultrasonography, malignant melanoma, melanoma thickness, indications of skin ultrasonography

\section{INTRODUCTION}

In recent years, high-frequency ultrasonography has become an important diagnostic tool in dermatovenerology. Ultrasound scanning is of importance in many aspects of clinical medicine (1). It has been a very important diagnostic method of organ and tissues imaging in medicine for about 60 years (2). The ultrasonography is a safe diagnostic method that can be performed at any place of the body and repeated for times without any risk to the patient.

The high-frequency ultrasonography was for the first time performed by Alexander and Miller for measuring skin thickness by using an A-mode device in 1979 (3). Great progresses in the development of high-frequency scanners in dermatovenerology occurred since that time (4).Highfrequency ultrasonography with $20 \mathrm{MHz}$ scanners is well-established for measuring thickness of the skin or its tumors and assessing inflammatory skin disorders (5). It provides information about the axial and lateral extension of benign, malignant processes, inflammatory processes of the skin and the subcutis and monitoring the effects of treatment of selected dermatoses $(1,2)$. Moreover, information about the quality of lesion and the inner structure (homogeneous, nonhomogeneous, hypoechogenic, hyperechogenic) can be obtained (1). Mild-frequency ultrasonography with 7.5-15 $\mathrm{MHz}$ sounds is widely used in dermatologic oncology, for preoperative staging and follow-up of melanoma patients, especially in investigation of lymph nodes (5).Currently, it is possible to achieve even higher resolution images using modern probes of a frequency of $50 \mathrm{MHz}$ or $100 \mathrm{MHz}$ that can be used for more detailed investigation of epidermal structures (2).

Indications for ultrasonography in dermatovenerology

The high-frequency $20 \mathrm{MHz}$ ultrasonography has a multiple indications in clinical and experimental dermatovenerology $(2,5)$ :

Address for correspondence:

MUDr.Andrea Kozárová, Dermatolovenerology Clinic of Martin University Hospital, Kollárova 2, 036 01 Martin; e-mail: andrejka.kozarova@gmail.com 
- Preoperative measurement of the thickness of malignant melanoma and other tumors

- Investigation of benign and malignant tumors of the skin

- Inflammatory processes of the skin and the subcutis / psoriasis, atopic dermatitis/

- Evaluation and monitoring of treatment of scleroderma-like diseases / morphea, eosinophilic fasciitis, cutaneous graft versus host disease/

- Monitoring the effects of treatment of selected dermatoses

- Unclear soft tissue swellings

- Sonographically guided intervention: targeted percutaneous needle biopsy of lymph nodes or sonographically navigated surgery

- Assessment of skin photoaging

- Evaluation of wound healing

- Assessment of the adverse effects of topical drug therapy

\section{METHODS}

All skin lesions were investigated with skin ultrasound Dermascan C - $20 \mathrm{MHz}$, Cortex Technology, Denmark (Fig.1). High-frequency $20 \mathrm{MHz}$ ultrasonography allows reliable imaging of cutaneous and superficial subcutaneous structures. With an axial resolution of $50 \mu \mathrm{m}$ and a lateral resolution of $300 \mu \mathrm{m}$, structures up to a depth of maximally $8 \mathrm{~mm}$ can be imaged. The conventional ultrasound focused on the region of interest to identify the lesion shape and echogenicity. The evaluation of a skin with $20 \mathrm{MHz}$ ultrasound B scan is performed from the surface to the depth. Hyperechogenic and hypoechogenic structures are distinguished: Hypoechogenic structures are those with fewer echoes than dermal connective tissue. Hyperechogenic structures are those with higher echogenicity than dermal connective tissue. The melanoma lesions had a homogeneous hypoechogenic appearance with a regular contour. Vertical tumor thickness is registered in millimetres, in relation to the thickness of the dermis.

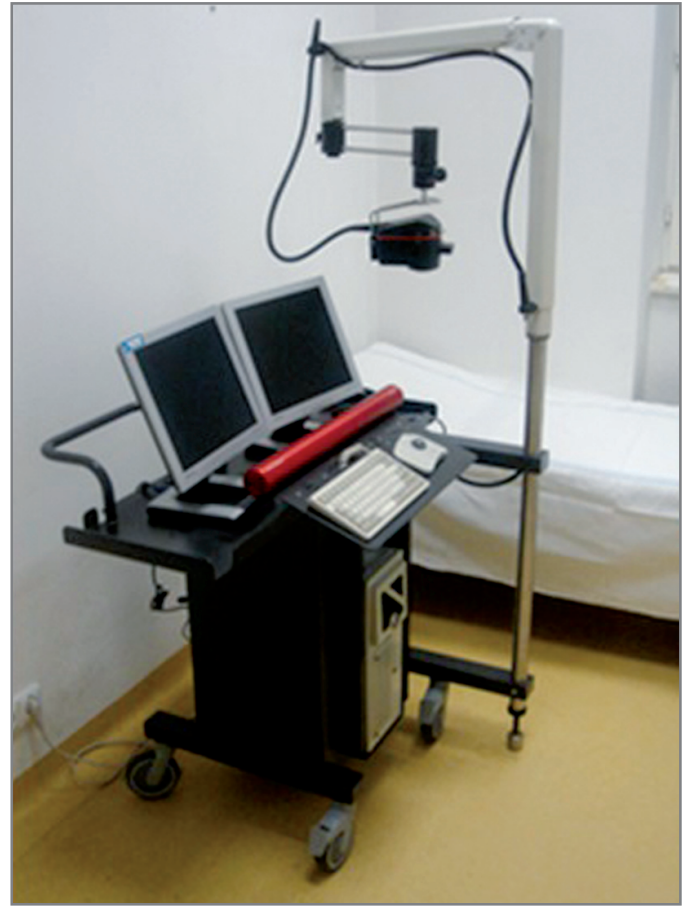

Fig.1 Dermascan C, CortexTechnology, Denmark 


\section{RESULTS}

In this article authors present principles of using high-frequency $20 \mathrm{MHz}$ ultrasonography in dermatovenerology.

\section{The normal skin ultrasonogram}

In normal skin the first layer is the epidermis that appears as a thin hyperechogenic and continuous line with homogeneous thickness (6). The echogenicity of the epidermis depends on the thickness of the stratum corneum and the amount of air contained between the keratotic scales (7). In some diseases can be visualised reduced echogenicity in the form of the low reflective band (hypoechogenic band) underneath the epidermis. It can be caused by infiltrates by inflammatory cells (atopic dermatitis, psoriasis) or of carcinomatous cells (Mycosis fungoides, T-cell lymphoma) (8).

Dermis is the next structure which is visualized on the ultrasound image of normal skin. Dermal echoes are variable and the echogenicity depends on the architecture of skin fiber network and on the amount of contained water, so all pathological changes on this level lead to reflexion reduction or production $(1,7)$. The dermis is visualized as a less echogenic as the epidermis and it is usually homogeneous, whereas the subcutaneous tissue is characteristically hypoechogenic (because of adipose tissue lobules), with the exception of connecting septa which are hyperechogenic. The borders between the epidermis and dermis, and between dermis and subdermal fat tissue are usually clear $(6,9)$.

A lot of studies were performed to find some differences of skin age thickness. Escoffier et al. reported that skin thickness increases between 0-30 years of age, in skin thickness between ages 15-65 is no significant variation and skin is significantly thinner before 15 and after 65 years (10).In the ultrasound image of the aged skin using high-frequency $20 \mathrm{MHz}$ ultrasonography we can see a subepidermal low echogenic band (SLEB). This band is not observed in the young. Its thickness increases proportionally with the age. The nature of this band is in papillary dermis - a well-vascularised area composed of thin collagen bundles. This hypoechogenic band corresponds to elastosis, changes in collagen structure and water accumulation $(11,12)$. SLEB thickness is used as a convenient parameter to measure skin aging. In contrast, the reticular dermis, composed of large collagen bundles, would correspond to the dermal echogenic band composed of larger wavy bundles, contains numerous voids filled by hydrated proteoglycans or glycosaminoglycans. This band is hyperechogenic and diminishes with age (13).

The evaluation of a skin with $20 \mathrm{MHz}$ ultrasound B scan is performed from the surface to the depth. Echo-poor or hypoechogenic structures are usually dark, echo-rich or hyperechogenic structures are usually bright in ultrasound image (5).

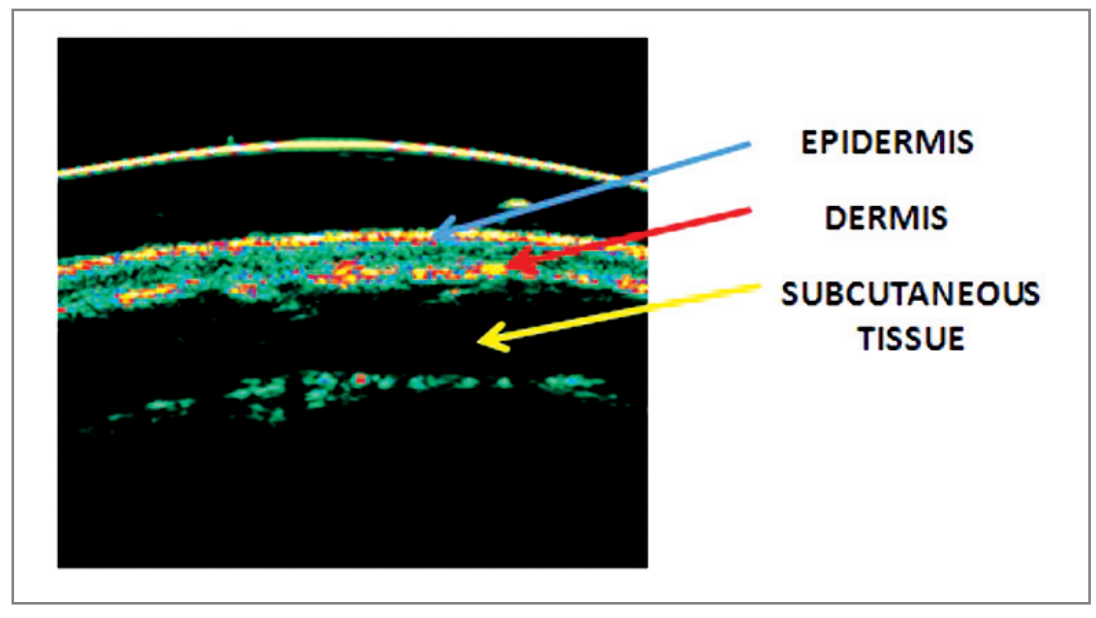

Fig. 2 The normal skin ultrasonogram 
In ultrasound image of normal skin we distinguish (Fig.2):

- Anechoic layer of gel

- The Epidermis

- The Dermis

- Subcutaneous tissue - hyperechogenic lines corresponding to the fibrous septa

- Muscle fascia - hyperechogenic line

\section{MALIGNANT MELANOMA}

Malignant melanoma is a frequent type of primary skin cancer and it has a high mortality rate. The standard treatment for melanoma is surgery. The histological depth of the tumor (Breslow thickness) is the most important factor for prognosis and treatment approach (14). Even though histology still represents the "gold standard' 'for the diagnosis of tumoral skin pathology, researchers were looking for new non-invasive methods of assessment that can offer reliable markers to the histological ones $(15,16)$.

The preoperative measurement of the thickness of malignant melanoma represents a new method for the non-invasive evaluation in dermatovenerology. During the last 30 years there were a lot of studies reported very good correlation between the tumoral depth, measured ultrasonographically and histologically $(14,17)$. Preoperative ultrasonographic measurement of tumour thickness could be an important parameter for planning surgery and predicting the prognosis for the patient (4).

On ultrasonography, the malignant melanoma appears as homogeneous and hypoechogenic, oval tumor, usually well delimited from dermis. Entry echo is clearly visible, but it can be less visible in ulcerated lesions (18) (Fig.3). In these cases the epidermis may be irregular or discontinuous, and increased echogenicity of the surrounding subcutaneous tissue may be found. Since the tumor can show asymmetry in its shape, the measurement of thickness should be performed at the deepest point (19).

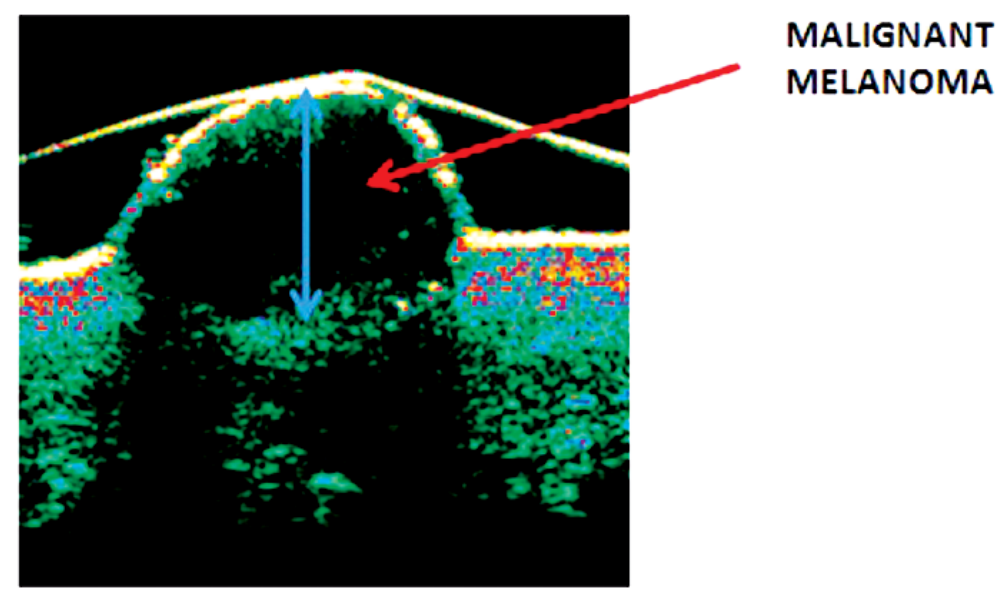

Fig.3 Malignant melanoma

\section{BASAL CELL CARCINOMA}

Basal cell carcinoma is the most common skin cancer, accounting for $80 \%$ to $90 \%$ of all cases. It is a malignant epidermal tumor, which is locally invasive and has a slow growth rate (20). Although it rarely metastasizes, morbidity results from local invasion and tissue destruction (21).

The diagnosis of basal cell carcinoma is made by macroscopic findings and histological examination. Ultrasonography of the lesions becomes another diagnostic method. The scars 
extirpations of the primary lesions can be investigated after radiotherapy and cryotherapy. The histological subtypes of basal cell carcinoma cannot be distinguished during the ultrasonographic investigation.

In high-frequency ultrasonography basal cell carcinomas are presented as solid, homogenous hypoechogenic oval lesions beneath a strong hyperechogenic epidermis with irregular borders. Histological subclassification of basal cell carcinomas could not be achieved with ultrasonography investigation $(1,22)$ (Fig.4).

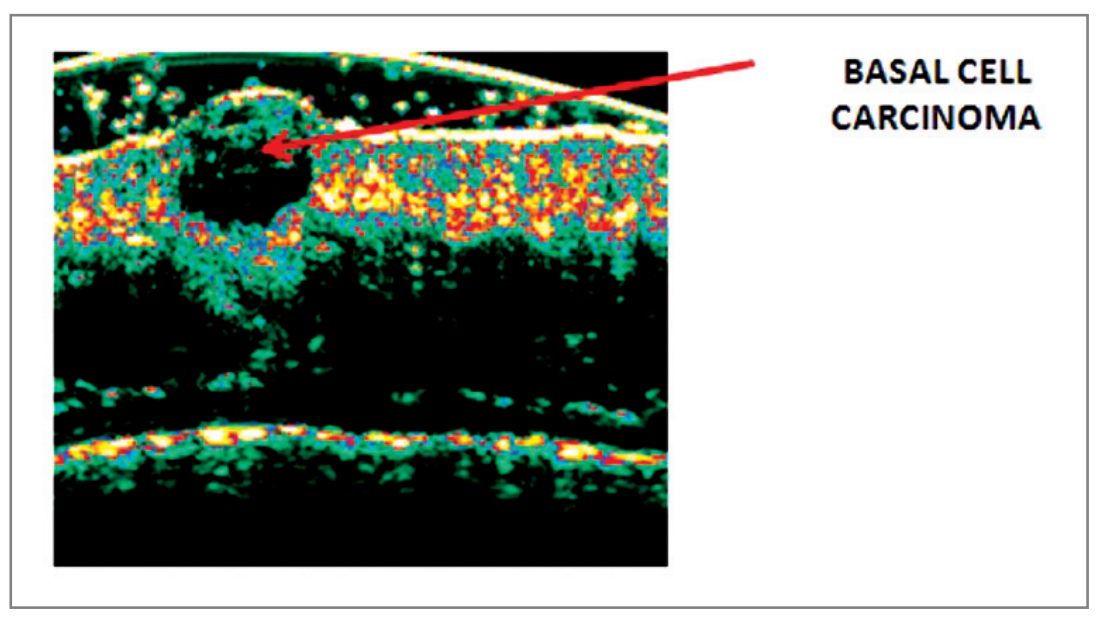

Fig.4 Basal cell carcinoma

\section{HEMANGIOMAS AND VASCULAR MALFORMATIONS}

Hemangiomas are benign endothelial cell neoplasms that appear in infancy and usually have a natural history of proliferation and involution (23). Hemangiomas are usually small or absent at birth. The lesions can appear as an erythematous macule, or an area of localized telangiectasia. Shortly after birth they undergo a proliferative phase, which can last for several months. They then undergo a stationary period, followed by a period of involution (24).

Vascular malformations are errors of morphogenesis and consist of abnormal channels lined by normal endothelium that has a low turnover. These anomalies are subclassified according to the predominant channel type (arterial, venous, capillary, lymphatic, or combinations thereof). Vascularmal formations are usually present at birth, but they may not become evident until adolescence or adulthood, and they persist throughout life (25). They usually grow proportionally with the child and are usually unresponsive to systemic treatments in contrast to hemangiomas. Therefore, differentiation between them is very important for adequate treatment (26).

In ultrasonography investigation hemangiomas are poorly defined solid tumors. The echogenicity vary according to their phase. In the proliferative phase they are hypoechogenic lesions with poorly defined borders (Fig.5). During the partial regression phase the echogenicity is heterogeneous, so they present on sonogram as a mix of hypoechogenic and hyperechogenic areas. In the regression phase, hemangiomas are hyperechogenic well-defined lesions $(27,28$, 29).

Vascular malformations can imagine as hypoechogenic tubules (arterial or venous), or hyperechogenic lesions (capillary) depending on the type of vessel. In venous malformations we can find hyperechogenic spots in hypoechogenic lesions that correspond to phleboliths. Assessment of the type (hyperechogenic, hypoechogenic, hyperechogenic spots in hypoechogenic lesions) thickness, and velocity of the vessels is useful for planning noninvasive (laser or percutaneous sclerotherapy) or invasive (embolization) treatments (30, $31)$. 


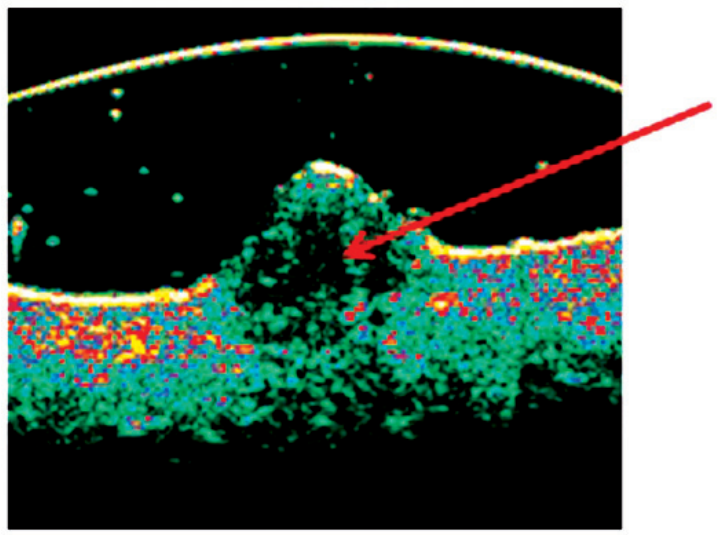

\section{SEBORRHEIC KERATOSES}

Seborrheic keratoses are epidermal in origin, superficial benign lesions. They are common in elderly. They are usually localized on the face, trunk and back. During the ultrasonography investigation, they have typical picture, which is specific for these lesions. In ultrasound imagine they present as hypoechogenic lesions with irregular thick surface, due to surface keratinization, in which one can see dense echoes - horny pseudocysts (Fig.6). This phenomenon differentiated them from melanomas and other benign nevi $(18,32,33)$.

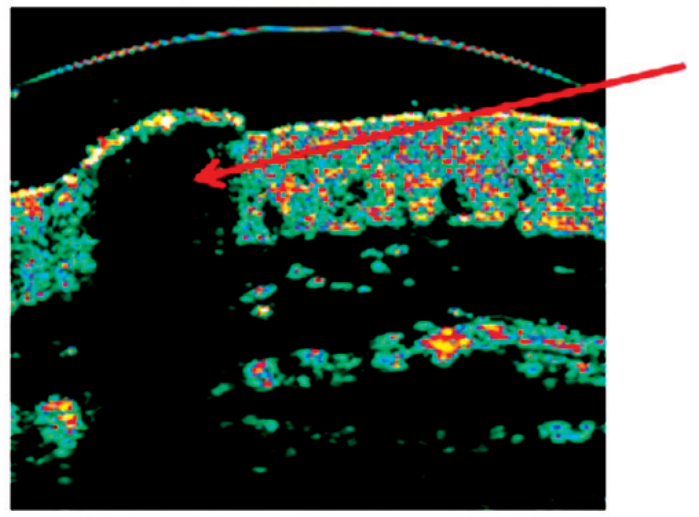

\section{SEBORRHEIC KERATOSIS}

Fig.6 Seborrheic keratosis

\section{PSORIASIS}

Psoriasis vulgaris is a chronic, genetically determined, inflammatory and proliferative skin disease, with a prevalence of $1-3 \%$ in the general population. Psoriasis commonly affects the skin and nails. The diagnosis of this disease has been based on both the clinical history and physical examination, and its severity is assessed by the Psoriasis Area and Severity Index. The high-frequency ultrasonography is usually used for monitoring of activity and the effect of treatment (6).

The ultrasonographic image of psoriatic plaque is characterized by varying increases in the width of the epidermis. The changes in epidermal thickness in the histological picture correspond to the zones of parakeratosis. During the acute inflammatory process, below the epidermis lies irregular, superficial, hypoechogenic band parallel with the surface of the skin $(4,9,34)$. This 
hypoechogenic band represents an akantotic epithel and inflammatory cellular infiltrate, and it shows disease activity (9).Another common ultrasonographic feature is a hypoechogenic band in the upper dermis, which may represent inflammatory edema and vasodilatation within the papillary dermis (35) (Fig.7).Thickening of both the epidermis and dermis is typical ultrasonographic pathologic finding in psoriatic plaques, the reduction or the disappearance of the hypoechogenic band at the superficial dermis level is the indicator of effective therapy $(36,37)$.

The similar ultrasonographic image is in photoaged skin. The stratum corneum of the epidermis may also show hyperkeratosis that can be seen as a thicker hyperechogenic line of the epidermis during ultrasonographic evaluation. A clearly visual subepidermal low echogenic band is located in the upper dermis immediately below the epidermal entrance echo. This corresponds to elastosis, changes in collagen structure - the replacement of mature collagen fibers of collagen with distinct basophilic appearance, and water accumulation. In contrast to psoriasis, where a subepidermal hypoechogenic band is created by inflammatory cells. The differential diagnosis between psoriasis and photoaged skin by ultrasonography alone is not possible and this diagnostic method cannot be used for it $(38,39)$.

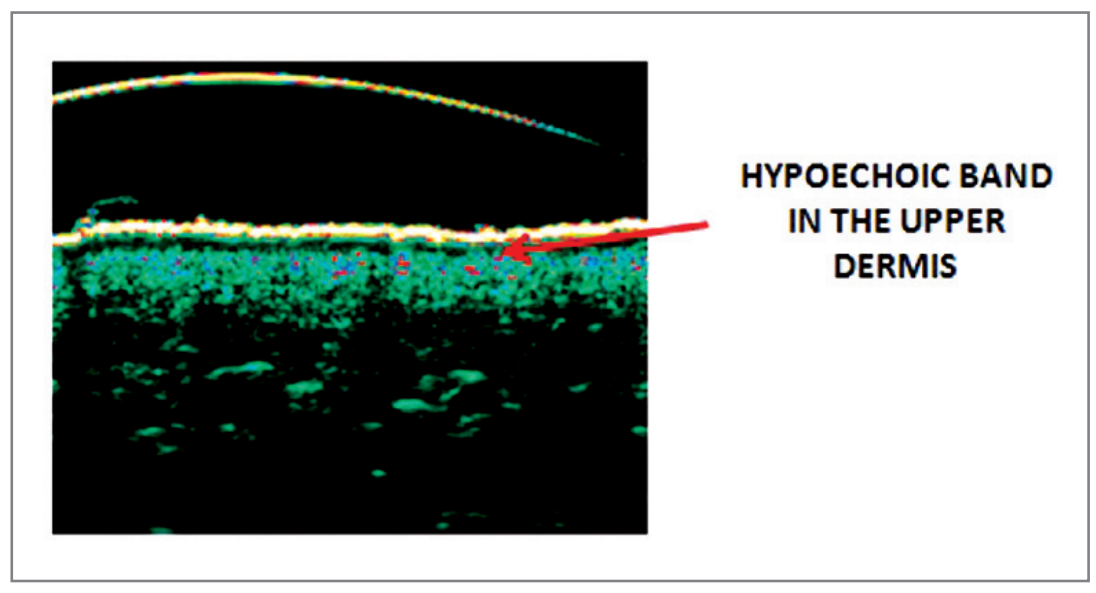

Fig.7 Psoriasis

\section{ATOPIC DERMATITIS}

Atopic dermatitis is a chronic, pruritic eczematous disease that usually begins in childhood and may continue throughout life. Clinical manifestations of atopic dermatitis result from interactions between an epidermal barrier dysfunction, immunological dysregulations, environmental factors and neurogenic disturbances (40). Atopic dermatitis has various clinical presentations depending on age. Infants usually have affected face or have generalized body eczema. Adults have eczema in flexural areas and on the hands (41).

In histological investigation during the acute phase, there is marked epidermal intercellular edema and a dermal inflammatory infiltrate of lymphocytes, and activated lymphocytes with normal numbers of mast cells that exhibited various degrees of hypogranulation. In chronic lesions there are increased numbers of Langerhans' cells in the epidermis. In lichenified plaques there is epidermal hyperplasia with a dermal inflammatory infiltrate that included increased numbers of mast cells, lymphocytes and macrophages (42).

A characteristic feature of an acute inflammatory process in ultrasonography is the hypoechogenic band beneath the epidermis that is caused by the intercellular edema (43) (Fig.8). In a chronic stage of the disease, there is also hypoechogenic band, but this is associated with reactive changes of the epidermis as well as the presence of subepidermal inflammatory infiltrates (8). The decrease of hypoechogenic band during therapy is a useful indicator of its effectiveness. This echolucent area is also visualized in other inflammatory skin disorders as psoriasis, due to the inflammatory infiltration, so it is not specific for atopic dermatitis (43). 


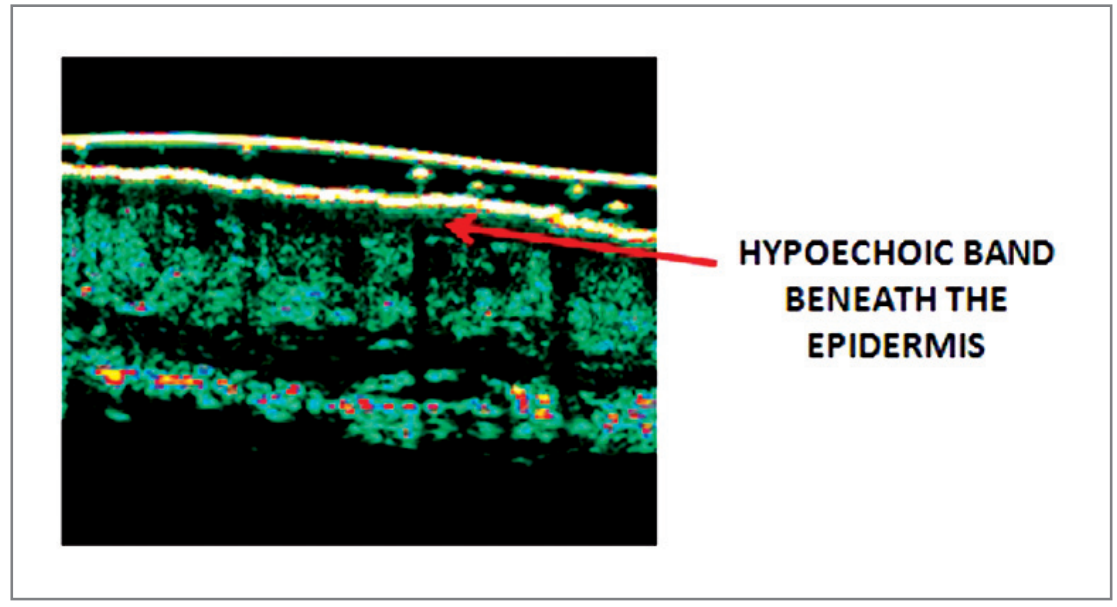

Fig.8 Atopic dermatitis - acute phase

\section{T- CELL LYMPHOMAS}

T-cell lymphomas are characterized by the presence of massive lymphocyte infiltration in the upper part of dermis. During the ultrasonography investigation, we can see the linear hypoechogenic band underneath the epidermis that is a dominant feature for this disease. It is caused by infiltrates of carcinomatous cells (Fig.9). Its reduction or disappearance, as in the case of inflammatory diseases as psoriasis or atopic dermatitis, shows the effectiveness of therapy $(2,8)$.

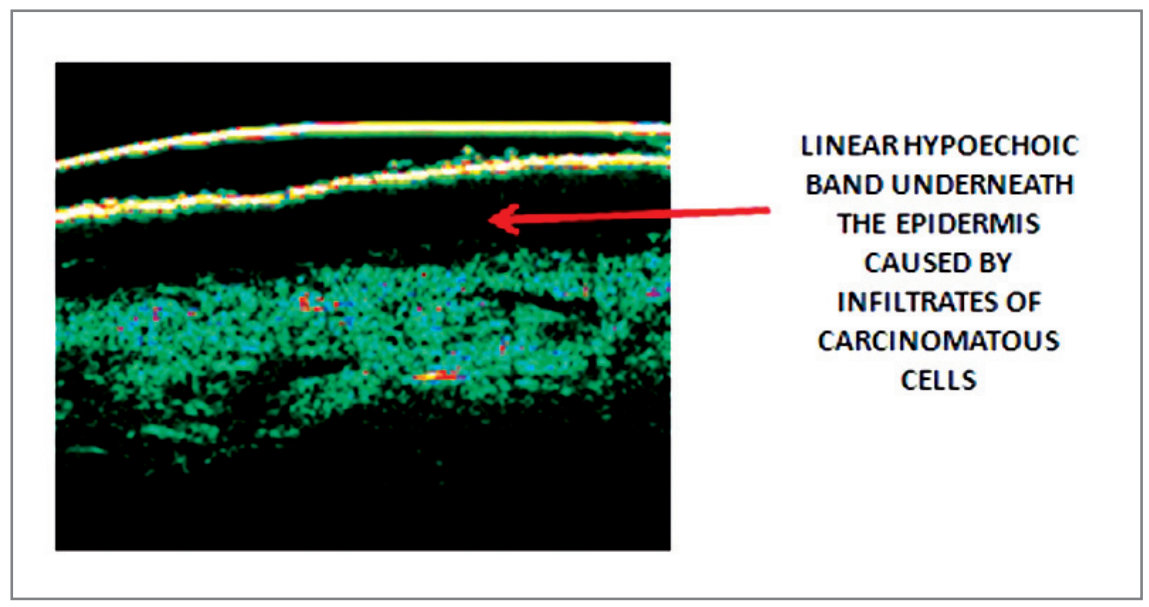

Fig.9 Cutaneous T-cell lymphoma

\section{CONCLUSION}

Dermatological ultrasound offers not only unique research opportunities, but also has significant clinical applications. It is a painless, low-risk and non-invasive procedure that can easily be performed and repeated. High-frequency ultrasound using 20-MHz transducers is well established for noninvasive imaging of the borders of skin tumors, especially malignant melanoma, the assessment of inflammatory skin diseases as psoriasis, atopic dermatitis, Tcell lymphomas and the measurement of skin thickness. Further progress in technology will lead to the development of higher resolution scanners. Despite these facts pathology examination remains the ultimate gold standard for diagnosis of skin tumors or other skin diseases. 


\section{REFERENCES}

1. Schmid-Wendtner MH, Burgdorf W. Ultrasound Scanning in Dermatology. Arch Dermatol 2005 Feb; 141 (2): 217-224.

2. Polańska A, Dańczak-Pazdrowska A, Silny W, Sadowska A, Jenerowicz D, Osmola-Mańkowska A, OlekHrab K. High-frequency ultrasonography in monitoring the effects of treatment of selected dermatoses. Dermatol Alergol 2011; XXVIII, 4: 255-260.

3. Alexander H, Miller DL. Determining skin thickness with pulsed ultrasound. J Invest Dermatol. 1979 Jan; 72 (1): 17-19.

4. Jasaitiene D, Valiukeviciene J, Linkeviciute G, Raisutis R, Jasiuniene E, Kazys R. Principles of highfrequency ultrasonography for investigation of skin pathology. JEADV 201 1; 25: 375-382.

5. Dill - Müller D, Masche J. Ultrasonography in dermatology. JDDG 2007; 5:689-707.

6. Gutierrez M, Wortsman X, Filippucci E, De Angelis R, Filosa G, Grassi W. High-Frequency Sonography in the Evaluation of Psoriasis Nail and Skin Involvement. J Ultrasound Med. 2009 Nov; 28(11): $1569-1574$.

7. Gniadecka M, Sondergaard J. Skin ultrasonography - clinical and experimental applications. Gulf J Dermatol 1995; 2(2): 27-31.

8. Polanska A, Danczak-Pazdrowska A, Silny W, Wozniak A, Maksin K, JenerowiczD, Janicka-Jedynska M. Comparison between high-frequency ultrasonography (Dermascan C, version 3) and histopathology in atopic dermatitis. Skin Res Technol. 2013 Nov; 19(4): 432-437.

9. Stojkovic T,Tiodorovic J, Ljubenovic M,Davidovic M. High frequency ultrasound in therapy effect assessment of fluocinolone acetonide in patients with psoriasis vulgaris. Acta Facultatis Medicae Naissensis. 2006; 23 (4): 203-207.

10. Escoffier C, De Rigal J, Rochefort A, Vasselet R, Leveque JL, Agache PG. Age-related mechanical properties of human skin: an in vivo study. J Invest Dermatol 1989; 93: 353-357.

11. Gniadecka M, Gniadecki R, Serup J, Søndergaard J. Ultrasound structure and digital image analysis of the subepidermal lowechogenic band in aged human skin: diurnalchanges and interindividual variability. J Invest Dermatol. 1994 March;102(3):362-365.

12. Waller JM, Maibach HI. Age and skin structure and function, a quantitative approach (I): blood flow, $\mathrm{Ph}$, thickness, and ultrasound echgenicity. Skin Res Technol. 2005 Nov; 11(4):221-35.

13. Rigal J, Escoffier C, Querleux B. Assessment of aging of the human skin by in vivo ultrasonic imaging. J Invest Dermatol 1989; 93: 621-625.

14. Crisan M, Crisan D, Sannino G, Lupsor M, Badea R, Amzica F. Ultrasonographic staging of cutaneous malignant tumors: an ultrasonographic depth index. Archives of Dermatological Research. 2013 May; 305 (4): 305-313.

15. Badea R, Crisan M, Lupsor M, Fodor L. Diagnosis and characterization of cutaneous tumors using combined ultrasonographic procedures (conventional and high resolution ultrasonography). Med Ultrason. 2010 Dec; 12(4): 317-322.

16. El Gammal S, El Gammal C, Kaspar K, Pieck C, Altmeyer P et al. Sonography of the skin at $100 \mathrm{MHz}$ enables in vivo visualization of stratum corneum and viable epidermis in palmar skin and psoriatic plaques. J Invest Dermatol. 1999 Nov; 113(5): 821-829.

17. Catalano O, Caraco C, Mozzillo N, Siani A. Locoregional spread of cutaneous melanoma: sonography findings. AJR Am J Roentgenol. 2010 Mar; 194(3): 735-745.

18. Machet L, Samimi M, Georgesco G, Mourtada Y, Naouri M, Grégoire JM, Ossant F, Patat F, Vaillant L. High Resolution Ultrasound Imaging of Melanocytic and Other Pigmented Lesions of the Skin, Ultrasound Imaging, Mr Masayuki Tanabe (Ed.), 2011, ISBN: 9789533072395

19. Wortsman X. Sonography of the Primary Cutaneous Melanoma: A Review. Radiology Research and Practice. Volume 2012; Article ID 814396; 6 pages

20. Nassiri-Kashani M, Sadr B, Fanian F, Kamyab K, Noormohammadpour P, Shahshahani MM, Zartab H, Naghizadeh MM, Sarraf-Yazdy M, Firooz A. Pre-operative assessment of basal cell carcinoma dimensions using high frequency ultrasonography and its correlation with histopathology. Skin ResTechnol. 2013 Feb; 19(1): 132-138.

21. Telfer NR, Colver GB, Morton CA. British Association of Dermatologists. Guidelines for the management of basal cell carcinoma. Br J Dermatol 2008; 159: 35-48.

22. Hinz T, Ehler L, Hornung T, Voth H, Fortmeier I, Maier T, Höller T, Schmid-Wendtner MH. Preoperative Characterization of Basal Cell Carcinoma Comparing Tumour Thickness Measurement by Optical Coherence Tomography, 20-MHz Ultrasound and Histopathology . Acta DermVenereol. 2012 Mar; 92(2):132-137. 
23. Burrows PE, Mulliken JB, Fellows KE, Strand RD. Childhood hemangiomas and vascular malformations: angiographic differentiation. American Journal of Roentgenology. 1983; 141: 483-488.

24. Donnelly F, Denise M. Adams D, George S. Bisset G. Vascular Malformations and Hemangiomas: A Practical Approach in a Multidisciplinary Clinic Lane. AJR Am J Roentgenol. 2000 Mar; 174(3): 597608.

25. Mulliken JB, Glowacki J. Hemangiomas and vascular malformations in infants and children: a classification based on endothelial characteristics. Plast Reconstr Surg 1982; 69: 412-422.

26. Mulliken JB, Glowacki J. Classification of pediatric vascular lesions. Plast Reconstr Surg 1982; 70 : $120-121$.

27. Paltiel HJ, Burrows PE, Kozakewich HP, Zurakowski D, Mulliken JB. Soft tissue vascular anomalies: utility of US for diagnosis. Radiology. 2000 Mar; 214(3): 747-754.

28. Peer S. The place of sonography in the diagnostic work-up of haemangiomas and vascular malformations. Handchir Mikrochir Plast Chir. 2009; 41 (2):70-77.

29. Wortsman X. Common applications of dermatologic sonography. J Ultrasound Med. 2012 Jan; 31(1): 97-111.

30. Paltiel HJ, Burrows PE, Kozakewich HP, Zurakowski D, Mulliken JB. Soft tissue vascular anomalies: utility of US for diagnosis. Radiology 2000; 214: 747-754.

31. Peer S. Theplace of sonography in the diagnostic work-up of haemangiomas and vascular malformations [in German]. Handchir Mikrochir Plast Chir 2009; 41: 70-77.

32. Harland C.C. Differentiation of common benign pigmented skin lesions from melanoma by high-resolution ultrasound. Br J Dermatol. 2000 Aug; 143(2): 281-289.

33. Mandava A, Ravun P, Konathan R. High-resolution ultrasound imaging of cutaneous lesions. Indian J Radiol Imaging. 2013 Jul-Sep; 23(3): 269-277.

34. Garbe C, Paul A, Kohler-Spath H, Ellwanger U, Stroebel W, Schwarz M, Schlagenhauff B, Meier F, Schittek B, Blaheta HJ, Blum A, Rassner G. Prospective Evaluation of a Follow-Up Schedule in Cutaneous Melanoma Patients: Recommendations for an Effective Follow-Up Strategy. J ClinOncol. 2003 Feb 1; $21(3): 520-529$.

35. Olsen LO, Serup J. High-frequency ultrasound scan for non-invasivecross-sectional imaging of psoriasis. Acta DermVenereol. 1993 Jun;73(3):185-187.

36. DiNardo A, Seidenari S, Giannetti A. B-scanning evaluation with image analysis of psoriatic skin. ExpDermatol. 1992 Oct; 1(3): 121-125.

37. Seidenari S. High-frequency sonography combined with image analysis: a noninvasive objective method for skin evaluation and description. Clin Dermatol. 1995 July-Aug; 13 (4): 349-359.

38. Berneburg M, Plettenberg H, Krutmann J.Photoaging of human skin. Photodermatol Photoimmunol Photomed. 2000 Dec;16(6 ):239-44.

39. Jane Sandby-Møller J, Wulf HC, Ultrasonographic subepidermal low-echogenic band, dependence of age and body site. Skin research and technology. 2004 Feb ; 10 (1): 57-63.

40. Boguniewicz M, Leung DY. Recent insights into atopic dermatitis and implications for management of infectious complications. J Allergy ClinImmunol. 2010 Jan; 125(1): 4-13.

41. Habif T.P et al.. Clinical dermatology. Elsevier Health Sciences, 2009, ISBN 0323080375

42. Soter N.Morphology of atopic eczema. Allergy. 1989; 44 Suppl 9: 16-19.

43. Dańczak-Pazdrowska A, Polańska A, Silny W, Sadowska A, Osmola-Mańkowska A, Czarnecka-Operacz M, Zaba R, Jenerowicz D. Seemingly healthy skin in atopic dermatitis: observations with the use of high-frequency ultrasonography, preliminary study. Skin Res Technol. 2012 May; 18(2): 162-167.

Received: September, 1,2016

Accepted: September,30,2016 